\title{
Estimating Dairy Young Stock Rearing Cost of Different Management Systems in Keningau, Sabah, Malaysia
}

X.T. Ang, N. Mohd Nor, M.W.H. Hiew, U. Khairuddin', C.T. Tan', M.I. Shapiai', N.A.M. Suhaimi', P.A.K. Lee ${ }^{3}$

10.18805/ajdfr.DR-217

\begin{abstract}
Background: Rearing young stock is costly, yet study on the economics of dairy young stock rearing in Malaysia is scarce. This study aims to determine the cost of rearing dairy young stock in different management system at the largest milk producer area located in Keningau, Sabah, Malaysia.

Methods: A survey was conducted at 7 smallholders, 6 semi-commercial sand 1 commercial dairy farms between July and August 2019 to estimate costs of rearing young stock from birth until first calving age (FCA) with the average number of milking cows as $16 \pm 2.495,40 \pm 3.256$ and 1,303 heads, respectively and the average number of young stocks was $2 \pm 0.769,14 \pm 4.578$ and 2,221 heads, respectively. Only feed costs were estimated. Data were analysed using IBM SPSS software.

Result: The average cost of rearing was RM4, 052 (USD1,000)/heifer across three different management systems, which were RM3,478 (USD858)/heifer in small scale, RM4,380 (USD1,081)/heifer) in semi-commercial and RM4,300 (USD1,061)/heifer) in commercial farms.
\end{abstract}

Key words: Dairy, Management, Rearing cost, Tropical, Young stock.

\section{INTRODUCTION}

The state of Sabah contributed $22.7 \%$ (9.2 million litres) of the total milk production in Malaysia in 2018 (DVS, 2018). Furthermore, 7.9 million litres of fresh milk produced in Sabah were produced by two commercial farms located in Keningau district contributing $90.6 \%$ (7.2 million litres) of Sabah's milk production. High input and high feed cost are the common challenges facing the dairy industry in Malaysia (Akila and Senthilvel, 2012; Sim and Suntharalingam, 2015) other than the domination of smallholders with minimal inputs and low milk yield (Saadiah et al., 2019).

The rearing of young stock as replacement for culled dairy cows is vital to maintain optimal herd size (Boulton et al., 2017) but often neglected (Moran, 2012) because it does not generate income for the farmer in the first 24 months (Hawkins, 2019). The rearing of dairy young stock in tropics is also challenged by the high tropical conditions of temperature and humidity (Moran, 2012) causing problems such as heat stress (Hernández-Castellano et al., 2019) and disease (Boersema et al., 2010), which could lower the number of replacement stock available and increase rearing costs (Mohd Nor et al., 2015).

Yet, the contributions of milk, herd size and number of smallholder dairy farms in Keningau have declined by $28 \%$ in 2018 as compared to 2017 (DVS and DFAS, unpublished data). There is insufficient research information on the feed management and cost of rearing dairy young stock in Malaysia (Devendra, 1984). It is needed to study the economics of the young stock enterprise in tropics to improve decision making in rearing management and lowering the rearing costs. The objective of this research is to estimate costs of rearing dairy young stock from birth to FCA under
Faculty of Veterinary Medicine, Universiti Putra Malaysia, 43400, UPM Serdang, Selangor, Malaysia.

${ }^{1}$ Universiti Teknologi Malaysia, Jalan Semarak, 54100, Kuala Lumpur, Malaysia.

'Universiti Sultan Zainal Abidin, Kampus Besut, 22200, Besut, Terengganu, Malaysia.

${ }^{3}$ Department of Veterinary Services Sabah (DVS), Wisma Pertanian Sabah, 88999, Kota Kinabalu, Sabah, Malaysia.

Corresponding Author: N. Mohd Nor, Department of Veterinary Preclinical Sciences, Faculty of Veterinary Medicine, Universiti Putra Malaysia, 43400, UPM Serdang, Selangor, Malaysia.

Email: norhariani@upm.edu.my

How to cite this article: Ang, X.T., Mohd Nor, N., Hiew, M.W.H., Khairuddin, U., Tan, C.T., Shapiai, M.I., Suhaimi, N.A.M. and Lee, P.A.K. (2021). Estimating Dairy Young Stock Rearing Cost of Different Management Systems in Keningau, Sabah, Malaysia. Asian Journal of Dairy and Food Research. 40(2): 136-141. DOI: 10.18805/ajdfr.DR-217.

Submitted: $28-12-2020 \quad$ Accepted: $15-04-2021 \quad$ Online: 30-04-2021

different Management Systems on Dairy Farms in Keningau, Sabah Malaysia.

\section{MATERIALS AND METHODS}

This study was conducted by the Faculty of Veterinary Medicine, UPM. At the beginning of the study, the list of dairy farms in Keningau district (5²0'00" N, 116 10'00" E) was obtained from the Department of Veterinary Services Sabah. Data on the total milk production and herd size per farm (2017-2019) were retrieved from the Dairy Farmers' Association (PPTS) and Dairy Industry Service Centre, Sabah (PPIT). Dairy farms categorized based on the number 
of milking cows (Sahu et al., 2012; Suntharalingam, 2019) which were small-scale (farm with 30 or fewer cows) $(n=7)$, semi-commercial (farms with 31-49 cows) $(n=6)$ and commercial (farms with more than 50 cows) $(n=1)$ were visited between July and August 2019 (Fig 2) to complete a questionnaire and to obtain yearly records of birth dates, number of living and dead young stock at different age from the semi-commercial and commercial farms.

\section{Questionnaire}

The questionnaire on rearing costs (Malay language) has 6 open-ended, 10 closed-ended and 1 semi-open questions organised into two sections; A: Background of the farm and $B$ : Feed costs and available upon request to the corresponding author.

\section{Data collection, editing and analysis}

Equation (1) was used to calculate the cost for each type of feed at different rearing period: i) birth to weaning age (i.e. raw milk and CMR); ii) weaning to conception age (i.e. concentrate) and iii) conception to first calving (i.e. concentrate) in each farm.

$$
\begin{aligned}
& \Sigma \text { Cost of rearing }= \\
& \left.\quad\left[\left(\text { Price }_{1,2,3 . . n} \times A m t_{1,2,3 . . n}\right) \times \text { Freq }\right) \times\left(\text { Period }_{i}\right)\right] \ldots(1)
\end{aligned}
$$

Where:

Price $_{1,2,3 . n}=$ Market price per $\mathrm{kg}$ or litre of feed (Different feed type 1,2,3..n) (RM).

$A m t_{1,2,3 . . n}=$ Amount given for feed type 1,2,3..n ( $\mathrm{kg}$ or litre). Freq= Number of feeding frequency per day (times).

Period $_{i}=$ Number of days during rearing period $i$.

Prices for feed used included unpasteurised whole milk (RM2.90/litre), CMR (RM336/25kg), dairy cattle pellet (RM81.20/50kg), total mixed ration (TMR) (RM46.50/50kg) and palm kernel cake (RM33/50kg). Only feed costs were considered in our study (USD1=MYR 4.05 currency convert 12 December 2020) as it represents the largest rearing costs (Mohd Nor et al., 2015).

We calculated the annual mortality of dairy young stock by using Equation (2), assuming death of calves in semicommercial farm occurred in the first year of life.

$$
\left(\Sigma \text { dead }_{n} / \Sigma \text { born }_{n}\right) \times 100 \% \ldots \ldots \ldots \ldots \ldots \ldots \ldots \ldots \ldots \ldots \ldots \ldots \ldots \ldots \ldots \ldots \ldots
$$

Where;

$\Sigma$ dead $_{\mathrm{n}}=$ Total number of dead young stock in year $\mathrm{n}$.

$\Sigma$ born $_{n}=$ Total number of young stocks born in year $n$.

Data was collected and edited using Microsoft Excel version 2019 (Microsoft Corp. Redmond, WA, USA) and analysed descriptively using IBM SPSS Statistics for Windows, version 25 (IBM Corp., Armonk, N.Y., USA).

\section{RESULTS AND DISCUSSION}

\section{Farm background}

All of the surveyed farms in this study used milking machine for collecting milk from dairy cows. Only the commercial farm has milk processing plant; the other farms sold their milk to
Dairy Industry Service Centre, Sabah (PPIT). From 2017 to 2019 , milk production decreased by $18 \%$ in smallholder farms but increased by $42 \%$ in the commercial farms and showed fluctuating trends in the semi-commercial farm (Table 1). The decreased milk production observed in smallholder dairy farms coincided with decreasing herd sizes during the period. However, the semi-commercial farms showed a higher milk production despite decreasing herd sizes. This phenomenon represents a trend towards specialisation and greater scale in commercial farming (ERSUS, 2006).

\section{The cost for rearing a dairy replacement heifer}

Our study showed that the average cost of rearing was RM3,478 (USD858)/heifer on the smallholder dairy farms, lower than costs of rearing at the semi-commercial dairy farms RM4,380 (USD1,081/heifer) and the commercial dairy farms RM4,300 (USD1,061/ heifer) (Fig 1). The average cost of rearing was lower than previous studies in The Netherlands (Mohd Nor et al., 2015), United States (Heinrichs et al., 2013) and United Kingdom (Hawkins, 2019) (Table 3) however the comparison is difficult due to different currency and management. Small holder farms in our study did not keep proper records on feeding, therefore costs after breeding to FCA could not be estimated in agreement with a previous study (Lokhande et al., 2012). However, the FCA in smallholder farms were on average higher than previous findings by (Moran and Brouwer, 2013) in tropical countries (30-36 months) could increase herd level costs (Mohd Nor et al., 2015). The FCA of the commercial farm falls within the recommended range for farms in tropical countries that uses Holstein crossbreeds (Konkruea et al., 2017) and could be due to proper breeding (Eastham et al., 2018), nutrition (Konkruea et al., 2017) and farm management (Moran, 2012).

This study revealed the period from birth to weaning as the most expensive rearing period among different management systems (Table 3 ) in agreement with a previous study (Hawkins et al., 2019). Calves in all farms $(n=14)$ were fed an average $5.2 \pm 2.42$ litres of cow's milk or calf milk replacer $(C M R)$ twice daily which is higher than the recommended range (4-5L) (Moran, 2012). From previous studies, calves fed whole milk from birth at a rate of $10 \%$ of live weight along with concentrate had a higher weaning weight and better post weaning growth rate (Bhatti et al., 2012; Santos and Bittar, 2015), nevertheless calves fed with CMR can grow equally well (Moran, 2012). Most of the smallholder and semi-commercial farms $(n=8)$ fed 4 litres/ calf/day raw milk. In contrast, the commercial farm fed 5 litres/calf/day of CMR (Table 3) which could be due to desire for producing high production cows (Erickson and Kalscheur, 2020) consequently lead to a heavier bodyweight of the calves (Silper et al., 2014) and higher feed costs (Uys et al., 2011 ) in commercial farms. Out of 14 surveyed farms, 12 $(86 \%)$ farms fed unpasteurised whole milk to their pre-wean calves and bought dairy cattle pellet to feed older young stock (Fig 3). While 2 (14\%) farms (semi commercial and commercial) fed CMR and own customised TMR to optimize 
Table 1: Farm descriptors for smallholder, semi-commercial and commercial dairy farms according to management system, milk pro duction, herd size and land size.

\begin{tabular}{lllc}
\hline \multirow{2}{*}{ Farm variables } & & Type of dairy farms & \\
\cline { 2 - 4 } & $\begin{array}{l}\text { Smallholder } \\
(\mathrm{n}=7) \text { mean } \pm \mathrm{SE}\end{array}$ & $\begin{array}{l}\text { Semi-commercial } \\
(\mathrm{n}=6) \text { mean } \pm \mathrm{SE}\end{array}$ & $\begin{array}{c}\text { Commercial } \\
(\mathrm{n}=1) \text { mean }\end{array}$ \\
\hline $\begin{array}{l}\text { Type of system } \\
\text { Definition }\end{array}$ & $\begin{array}{l}\text { Semi-intensive } \\
\text { combination of limited grazing and } \\
\text { stall feeding (Bandara et al., 2011) }\end{array}$ & $\begin{array}{l}\text { Intensive } \\
\text { animal are housed in a free-stall } \\
\text { system (Passetti et al., 2016) }\end{array}$ & Intensive \\
Milk production (liters) & $39,117.97 \pm 5,903$ & $93,541 \pm 22,900.16$ & $2,950,584$ \\
2017 & $33,007.33 \pm 7,164$ & $85,307 \pm 20,116.72$ & $3,682,346$ \\
2018 & $32,249.71 \pm 7,805$ & $92,729 \pm 23,345.99$ & $4,236,237$ \\
2019 & & & \\
Herd size (number of milking cows) & $21 \pm 1.724$ & $43 \pm 4.072$ & 1,697 \\
2017 & $21 \pm 3.415$ & $57 \pm 6.770$ & 1,230 \\
2018 & $16 \pm 2.495$ & $40 \pm 3.256$ & 1,303 \\
2019 & $10.86 \pm 3.98$ & $21.33 \pm 11.50$ & 277 \\
Land size (acres) & & & \\
\hline
\end{tabular}

Table 2: The demographic of respondent with farms grouped into smallholder, semi-commercial and commercial dairy farms based on number of milking cows available on the farms.

\begin{tabular}{|c|c|c|c|}
\hline \multirow[b]{2}{*}{ Demographic information } & \multicolumn{3}{|c|}{ Types of farms } \\
\hline & $\begin{array}{l}\text { Smallholder } \\
\qquad(\mathrm{n}=7)\end{array}$ & $\begin{array}{l}\text { Semi-commercial } \\
\qquad(n=6)\end{array}$ & $\begin{array}{c}\text { Commercial } \\
(n=1)\end{array}$ \\
\hline \multicolumn{4}{|l|}{ Gender } \\
\hline Male & $5(71)$ & $6(100)$ & $1(100)^{1}$ \\
\hline Female & $2(29)$ & $0(0)$ & $0(0)$ \\
\hline \multicolumn{4}{|l|}{ Age (months) } \\
\hline $21-30$ & $0(0)$ & $2(33)$ & $1(100)^{1}$ \\
\hline $31-40$ & $3(43)$ & $1(17)$ & $0(0)$ \\
\hline $41-50$ & $2(29)$ & $1(17)$ & $0(0)$ \\
\hline $51-60$ & $2(29)$ & $2(33)$ & $0(0)$ \\
\hline \multicolumn{4}{|l|}{ Race } \\
\hline Malay & $2(29)$ & $0(0)$ & $0(0)$ \\
\hline Chinese & $4(57)$ & $3(50)$ & $0(0)$ \\
\hline Indian & $0(0)$ & $0(0)$ & $1(100)^{1}$ \\
\hline Others & $1(14)$ & $3(50)$ & $0(0)$ \\
\hline \multicolumn{4}{|l|}{ Level of education } \\
\hline Secondary & $6(86)$ & $4(67)$ & $0(0)$ \\
\hline Tertiary & $1(14)$ & $2(33)$ & $1(100)^{1}$ \\
\hline \multicolumn{4}{|c|}{ Period of experience in dairy farming (years) } \\
\hline Less than 10 & $3(43)$ & $4(67)$ & $1(100)^{1}$ \\
\hline Between 11 and 20 & $4(57)$ & $0(0)$ & $0(0)$ \\
\hline More than 20 & $0(0)$ & $2(33)$ & $0(0)$ \\
\hline \multicolumn{4}{|c|}{ Experience in purchasing replacement heifer } \\
\hline Yes & $4(57)$ & $2(33)$ & $1(100)^{1}$ \\
\hline No & $3(43)$ & $4(67)$ & $0(0)$ \\
\hline \multicolumn{4}{|c|}{ Intention to increase herd size } \\
\hline Yes & $7(100)$ & $4(67)$ & $1(100)^{1}$ \\
\hline No & $0(0)$ & $2(33)$ & $0(0)$ \\
\hline
\end{tabular}

Survey was conducted to manager of the dairy farm, while survey at other farms were conducted with the owner. 

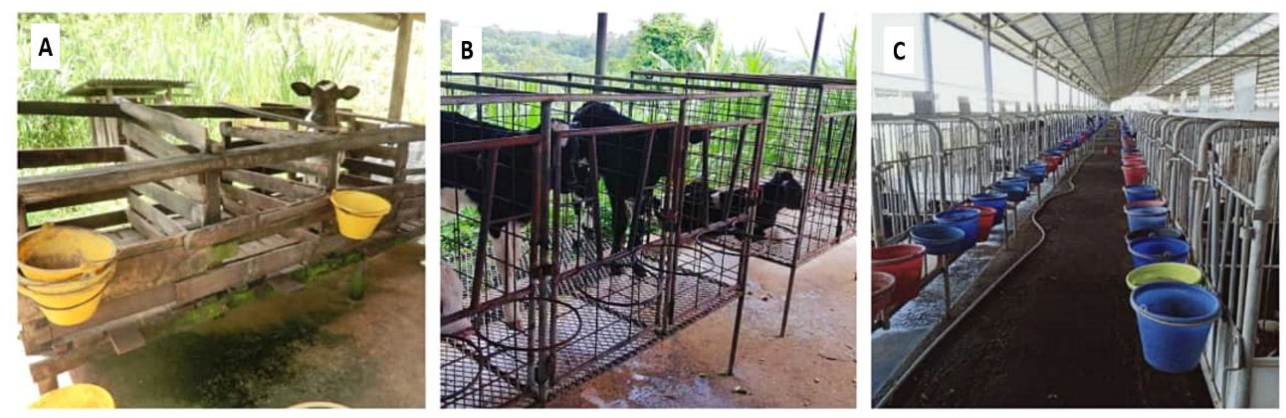

Fig 1: Young stock rearing in dairy farm in Malaysia; A: Small-scale farm, B: Semi commercial farm, C: Commercial farm. Dairy farmers in Malaysia kept the pre-weaning calf in individual pens with different feeding management practices. Majority of farmers fed whole milk and minority fed calf milk replacer.
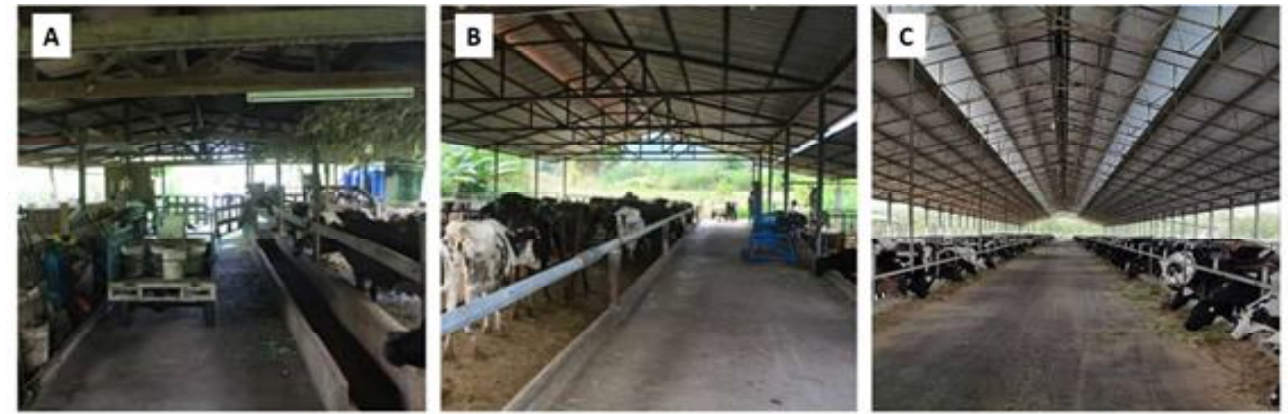

Fig 2: Different management systems in dairy farm in Malaysia; A: Small-scale farm, B: Semi commercial farm, C: Commercial farm. Small-scale farm is with 30 or fewer cows, semi-commercial are farms with 31-49 cows and commercial farms are with more than 50 milking cows.
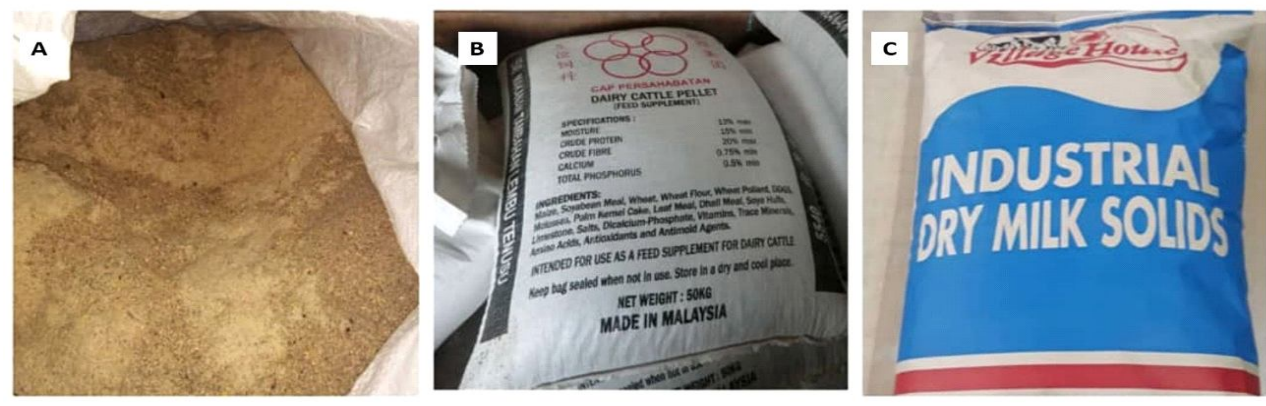

Fig 3: The types of feed provided to the dairy young stock, A: Total mix ration, B: Dairy cattle pellet, C: Calf milk replacer. Total mixed ration was the mixture of palm kernel cake, pollard, fish meal, salt, corn bran and rice bran. Instead of providing total mixed ration, there are farmers provided dairy cattle pellet. Calf milk replacer was provided by one of the semi-commercial farm and commercial farm for pre-weaning calf.

Table 3: The age and estimated feed cost for rearing dairy replacement heifer in Keningau, Sabah, Malaysia.

\begin{tabular}{|c|c|c|c|}
\hline Period / farm types & Smallholder $(n=7)$ & Semi-commercial $(n=6)$ & Commercial $(n=1)$ \\
\hline & \multicolumn{3}{|c|}{ Age (months) (Average \pm SE) } \\
\hline Weaning & $3 \pm 0.11$ & $2.8 \pm 0.08$ & 3 \\
\hline Start breeding & $27 \pm 2.51$ & $19.2 \pm 1.2$ & 15 \\
\hline \multirow[t]{2}{*}{ First calving } & $39 \pm 1.33$ & $31 \pm 1.44$ & 24 \\
\hline & \multicolumn{3}{|c|}{ Costs (RM) (Average $\pm S E)^{1}$} \\
\hline Birth to weaning & $1,443 \pm 276.59$ & $1,194 \pm 289.92$ & 868.50 \\
\hline Weaning to breeding & $1,372 \pm 44.11$ & $1,685 \pm 356.70$ & $1,771.20$ \\
\hline Breeding to first calving ${ }^{2}$ & - & $1,600 \pm 282.15$ & $1,660.50$ \\
\hline Total & $3,478.8 \pm 382.87$ & $4,380 \pm 584.21$ & $4,300.20$ \\
\hline
\end{tabular}

1The rearing costs only include feed cost (milk, CMR, own TMR, dairy cattle pellet and palm kernel cake).

${ }^{2}$ Smallholder dairy farmers are unable to provide the amount of feed given to young stock. 
costs of rearing. Previous study revealed CMR was lower $(50 \%)$ than the cost of unpasteurised raw milk (Moran, 2012), but further studies are required using the current price of CMR and different growth performance. Nevertheless, farmers who preferred raw milk believed high technical skill is needed in preparing CMR in order to avoid complications of diarrhoea and mortality. Insufficient technical skill on CMR and TMR among farmers in this study could hinder the productivity of smallholder dairy farms (Tawaf and Russanti, 2017).

To our knowledge, our study is the first to show average mortality rate in commercial dairy farm in Malaysia. Calf death in the semi-commercial farm was recorded without specifying the actual date but previous studies reported that calf mortality occurred mostly in the first year (Lora et al., 2014). The annual mortality rate of dairy young stock in the commercial farm from birth until FCA (2015-2019) was 9\% (7\%-10\%) and the average mortality rate from birth to 12 months (2014-2018) in one of the semi-commercial farms was $21 \%(11 \%-32 \%)$ in agreement with a previous study conducted in tropics (Moran, 2012). As our result is higher than the mortality reported in UK (6\%) (Lorenz et al., 2011) and Australia (3\%) (McNeil, 2009), more emphasis must be placed on the proper calf management and recording of calf mortality data because most farms might underestimate the problem.

The difficulty in calculating feed cost is evident especially to smallholder farm, in our case, the small sampling size is justified (Table 2) due to the time inquiring the detailed feed management and costs of rearing young stock, in a comparable environmental conditions and represented $20 \%$ of all dairy farms and $90.6 \%$ of total milk production in state of Sabah. Previous similar studies showed the high cost of rearing young stock (Boulton et al., 2017) and consequently the additional calf mortality could influence sustainability of dairy farms (Kochewad et al., 2013) thus, government should support farmers to keep a proper record for instance by using computer vision to improve individual record keeping (Vate-U-Lan et al., 2017) but more research needs to be done on the costeffectiveness and its applicability to smallholder dairy farms.

\section{CONCLUSION}

The average cost of rearing was RM4, 052 (USD1, 000)/ heifer across three different management systems, which were RM3,478 (USD858)/heifer in small scale, RM4,380 (USD1,081)/heifer) in semi-commercial and RM4,300 (USD1,061)/heifer) in commercial dairy farm.

\section{Conflict of interest}

The authors declare there is no conflict of interest.

\section{ACKNOWLEDGEMENT}

The authors would like to acknowledge DVS Sabah for their support and Malaysian Research University Networks (MRUN) for the funding of Project 324927 (MRUN/2020/ 5539500) Title: Precision veterinary surveillance system to support dairy young stock rearing decisions.

\section{REFERENCES}

Akila, N. and Senthilvel, K. (2012). Status of Dairy Farming in Karur District of Tamil Nadu. Indian Journal of Animal Research. 46: 401-403.

Bandara, D., Premaratne, S. and Dematawewa, C. (2011). Production and economic characteristics of intensive and semi- intensive dairy cattle management systems in vegetable based farming system in welimada, Sri Lanka. Tropical Agricultural Research. 22(3): 314. https:/ /doi.org/10.4038/tar.v22i3.3704.

Bhatti, S.A., Ali, A., Nawaz, H., McGill, D., Sarwar, M., Afzal, M., Khan, M.S., Ehsanullah, Amer, M.A., Bush, R., Wynn, P.C. and Warriach, H.M. (2012). Effect of pre-weaning feeding regimens on post-weaning growth performance of Sahiwal calves. Animal. 6(8): 1231-1236. https://doi.org/ 10.1017/S1751731112000250.

Boersema, S.J., da Silva, J.C., Mee, J. and Noordhuizen, J. (2010). Farm health and productivity management of dairy young stock. In Farm Health and Productivity Management of Dairy Young Stock. https://doi.org/10.3920/978-90-8686694-6.

Boulton, A.C., Rushton, J. and Wathes, D.C. (2017). An empirical analysis of the cost of rearing dairy heifers from birth to first calving and the time taken to repay these costs. Animal. 11(8): 1372-1380. https://doi.org/10.1017/ S1751731117000064.

Devendra, C. and I.E. (1984). Improvement of raising method of dairy calves in malaysia energy sources for calf starter rations. National Istitute of Animal Industry. 148: 157.

dos Santos, G. and Bittar, C.M.M. (2015). A survey of dairy calf management practices in some producing regions in Brazil. Revista Brasileira de Zootecnia. 44(10): 361-370. https://doi.org/10.1590/S1806-92902015001000004.

Eastham, N.T., Coates, A., Cripps, P., Richardson, H., Smith, R., and Oikonomou, G. (2018). Associations between age at first calving and subsequent lactation performance in UK Holstein and Holstein-Friesian dairy cows. PLOS ONE. 13(6): 1-13. https://doi.org/10.1371/journal.pone.0197764.

Economic Research Service United States Department of Agriculture (ERSUS). (2006). Changes in the size and location of U.S. Dairy Farms. Profits, Costs and the Changing Structure of Dairy Farming. ERR-47: 2-4.

Erickson, P.S. and Kalscheur, K.F. (2020). Nutrition and feeding of dairy cattle. Animal Agriculture. January. 157-180. https://doi.org/10.1016/b978-0-12-817052-6.00009-4.

Hawkins, A., Burdine, K., Amaral-Phillips, D. and Costa, J.H.C. (2019). An economic analysis of the costs associated with pre-weaning management strategies for dairy heifers. Animals. 9(7): 1-11. https://doi.org/10.3390/ani9070471.

Hawkins, A.C. (2019). Evaluating Costs Associated With Management Decisions of Replacement Dairy Heifers and Their Impact on the Total Rearing Investment.

Heinrichs, A.J., Jones, C.M., Gray, S.M., Heinrichs, P.A., Cornelisse, S.A. and Goodling, R.C. (2013). Identifying efficient dairy heifer producers using production costs and data envelopment analysis. Journal of Dairy Science. 96(11): 7355-7362. https://doi.org/10.3168/jds.2012-6488. 
Hernández-Castellano, L.E., Nally, J.E., Lindahl, J., Wanapat, M., Alhidary, I.A., Fangueiro, D., Grace, D., Ratto, M., Bambou, J.C., and de Almeida, A.M. (2019). Dairy science and health in the tropics: challenges and opportunities for the next decades. Tropical Animal Health and Production. 51(5): 1009-1017. https://doi.org/10.1007/s11250-019-01866-6

Kochewad, S.A., Singh, J.P., Patil, V.M., Kumar, V. and Bhokre, S.M. (2013). Calf mortality causes and control measures. Indian Farming 62(10): 23-26.

Konkruea, T., Koonawootrittriron, S., Elzo, M. A. and Suwanasopee, T. (2017). Genetic parameters and trends for daughters of imported and Thai Holstein sires for age at first calving and milk yield. Agriculture and Natural Resources. 51(5): 420-424. https://doi.org/10.1016/j.anres.2017.12.003.

Lokhande, J.P., Jha, S.K. and Vaidya, M.D. (2012). Constraints perceived by the dairy farmers in adoption of scientific dairy farming practices in Sikar district. Journal of Dairying. Foods and Home Sciences. 31(1): 42-46.

Lora, I., Paparella, P., Brscic, M. and Gottardo, F. (2014). Survey on mortality rate of young stock on dairy farms of the Province of Padova. Acta Agraria Kaposváriensis. 18: 69-74.

Lorenz, I., Fagan, J. and More, S.J. (2011). Calf health from birth to weaning. II. Management of diarrhoea in pre-weaned calves. Irish Veterinary Journal. 64(1): 1-8. https://doi.org/ 10.1186/2046-0481-64-9.

McNeil, J., (2009). Calf management across the supply chain The calf supply chain maintains an excellent reputation for production of veal that meets required food industry standards. Dairy Australia. 1-14.

Mohd Nor, N., Steeneveld, W., Mourits, M.C.M. and Hogeveen, H. (2015). The optimal number of heifer calves to be reared as dairy replacements. Journal of Dairy Science $98(2)$ : 861-871. https://doi.org/10.3168/jds.2014-8329.

Moran, J. (2012). Rearing Young Stock on Tropical Dairy Farms in Asia. In Rearing Young Stock on Tropical Dairy Farms in Asia. https://doi.org/10.1071/9780643107915.

Moran, J.B. and Brouwer, J. W. (2013). Interrelationships between measures of cow and herd performance and farm profitabilty. International Journal of Agriculture and Biosciences. 2(5): 221-233.
Passetti, R.A.C., Eiras, C.E., Gomes, L.C., dos Santos, J.F. and do Prado, I.N. (2016). Intensive dairy farming systems from Holland and Brazil: SWOT analyse comparison. Acta Scientiarum - Animal Sciences. 38(4): 439-446. https:/ /doi.org/10.4025/actascianimsci.v38i4.31467.

Saadiah, J., Predith, M., Azizah, A. and Shanmugavelu, S. (2019). Formulation and evaluation tool of dairy cattle rations for smallholders. Malaysian Journal of Veterinary Research. 17(2): 1-12.

Sahu, N.C., Gupta, J., Singh, A.K., and Chaudhari, B.K. (2012). Viability of Commercial Dairy Farming in Haryana. Journal of Dairying, Foods and Home Sciences. 31(3): 216-222.

Silper, B.F., Lana, A.M.Q., Carvalho, A.U., Ferreira, C.S., Franzoni, A.P.S., Lima, J.A.M., Saturnino, H.M., Reis, R.B. and Coelho, S.G. (2014). Effects of milk replacer feeding strategies on performance, ruminal development and metabolism of dairy calves. Journal of Dairy Science. $97(2)$ : 1016-1025. https://doi.org/10.3168/jds.2013-7201.

Sim, R.M.L. and Suntharalingam, C. (2015). Dairy Sector in Malaysia: A Review of Policies and Programs. FFTC Agricultural Policy Articles. 33: 1-5. http://ap.fftc.agnet.org/files/ ap_policy/501/501_1.pdf.

Suntharalingam, C. (2019). Marketing Mix of Milk and Dairy Products in Peninsular Malaysia. In ERIA Research Project Report (Issue 5).

Tawaf, R. and Russanti, F. (2017). Impact of Production Efficiency and Appropriate Technology to Smallholder Dairy Farm's Revenue. KnE Life Sciences. 2(6): 396. https://doi.org/ 10.18502/kls.v2i6.1061.

Uys, J.L., Lourens, D.C. and Thompson, P.N. (2011). The effect of unrestricted milk feeding on the growth and health of Jersey calves. Journal of the South African Veterinary Association. 82(1): 47-52. https://doi.org/10.4102/jsava.v82i1.33

Vate-U-Lan, P., Quigley, D. and Masoyras, P. (2017). Smart Dairy Farming through Internet of Things (lot). Asian International Journal of Social Sciences. 17(3): 23-36. https://doi.org/ 10.29139/aijss.20170302. 